\title{
Why is Sport and Develop- ment a Priority in National Sport Organizations?
}

\section{REASON \#1: SOLIDARITY}

Danish Gymnastics and Sport Associations (DGI) has run sport and development projects for many years, predominantly in East Africa. A significant part of the discourse with the key leaders involved was that the work should constitute "acts of solidarity". In my interpretation, that translates into a desire to provide unilateral assistance to someone in need without necessarily expecting something in return. Taken to the extreme, the solidarity argument basically defines sport and development work as a moral obligation.

The logic behind the solidarity argument is that such work is done not for the benefit of the donor organization, but solely for that of the recipients (individuals and organizations).

\section{CONSEQUENCES:}

The solidarity argument is an interesting test for any organization. It would be safe to say that the level of involvement in such solidarity work must be determined politically as there are no limits to how much help is actually needed world-wide. However, political decision-making by governments as well as by sports organisati-

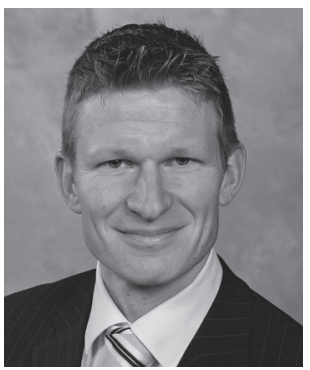

BY

JACOB

SCHOUENBORG

ons is not always stable or reliable and this vagueness impinges on the solidarity argument, making it problematic for its proponents.

The solidarity argument also highlights the inequality that is inherent in the majority of sport and development projects: It is about someone "better off" assisting someone "worse off", creating formal and mental structures that reinforce rather than reduce inequality.

\section{REASON \#2: SPORT DEVELOPMENT}

A sport organization may see its goal as engaging as many people world-wide as possible in 


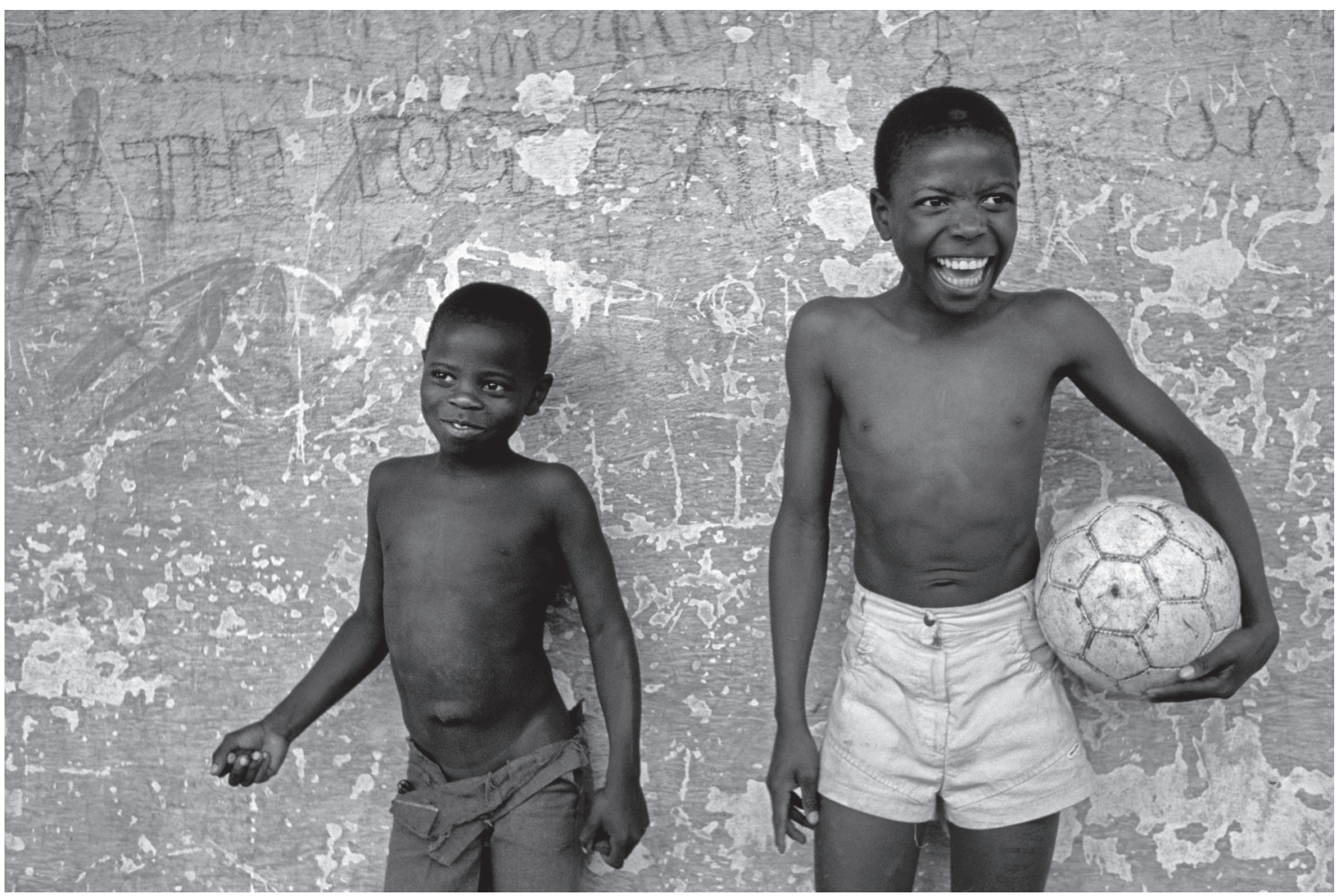

Street children standing against a wall, Kampala, Uganda (Photo: Caroline Penn/Scanpix).

sport, perhaps even a particular sport. FIFA, notably, with its 'Football for Hope' program, arguably focuses solely on getting more people involved in football (and consequently expect that positive effects of football will follow). However, national sport organizations use the "sport development" argument as well. The Norwegian Sport Confederation (NIF) is currently revisiting sport development arguments in its work in Africa. After all, this is what they are good at, the argument goes. Some national sport organizations are more political and distinguish between different paradigms in sport trying to pro- mote their own within the broader "Sport for All" paradigm, in contrast to elite and professional sport. French UFOLEP (Union Française des Oeuvres Laïques d'Education Physique) is one example, with its motto, "Une autre idée du sport" (another idea of sport).

\section{CONSEQUENCES:}

Sport development arguments are inherently biased because they assume that sport is good in itself: The more sport (football?), the better. Yet, racism, doping, violence, cheating and exclusion continue to be observed in sport (and not just in 
top sport). It is necessary, however, to define what kind of sport and what effects of that sport one anticipates. Unfortunately this is also a huge challenge. It is difficult to assess the impact of developmental work in itself on community building, social capital, life skills, and inclusion. Yet it is twice as difficult to measure the contribution of a specific sport program on these same variables. Whether sports can be considered as the most effective tool to use for developmental purposes is also questionable.

Why should one particular sport be promoted over another? For example, is football a better means of promoting integration than basketball? Indeed, why not focus on the game, the physical activity and the playing itself? I understand the attraction of playing a globally recognized game like football, and having mega stars as role models, however, it is not a very culturally sensitive approach, nor practical in terms of its requirement of a $90 \times 45 \mathrm{~m}$ grass pitch and playing strictly "by the rules". NIF, a reputable sport and development organization, offers selfcritique about its earlier attempts of enthusiastically promoting aerobics and gymnastics in Africa.

"Sport development" argumentation is also observed in professional (football) leagues' activities. Danish top league football teams FC København and FC Midtjylland have been involved in establishing football schools in South Africa and Ghana respectively. There has been little attempt to hide the fact that they identified and exported talented players from these countries to Denmark to play professionally. Yet they were also argued to contribute to the sport development in the country. One could argue that their contribution amounted simply to instilling false expectations.

\section{REASON \#3: POLITICS}

The Canadian Heritage and the Australian Sport Commission, although not national sport NGOs, are very active in sport and development work. This can be considered as part of the broader political strategy of their governments. In Australia, a country that differs from most of its neighboring countries, developmental aid (that includes sport) is a natural consequence of its geo-political positioning within the region. Canada, similarly known for its pro-active international profile, focuses in particular on peacebuilding efforts. And sports is seen as a useful tool in this connection.

Distinctly different is Italian UISP (Unione Italiana sport per Tutti); one of 13 grass-roots sport organizations that were established by national political parties in Italy, and in this particular case by the Communist Party. Although the direct political party link has faded today, UISP still has a strong political legacy. It maintains a very high profile of promoting the rights of the weakest residents in Italian society (immigrants, prison inmates, Romas, etc.) to participate in sport. It also founded the NGO, "Peace Games", that extends this work in the Balkans, the Middle East and Africa. This is the political identity and image that this organization promotes.

The Olympic Games, to be held in London in 2012, have a large scale Legacy program. More than 25 million pounds are spent on sport projects around the world. The projects supposedly benefit from the London Olympic Games as a "guiding star" for sport development all over the world. Politically, this is probably easier to sell for the London organizers than " 14 days of televised entertainment in top elite sport". But where is the link between a PE teacher's curri- 
culum project in Baku, Azerbaijan, and the technology-driven Olympic 100m dash held in London?

Finally, some Western European countries and organizations have a tendency to focus their sports development programs in countries that were former colonies, e.g. the French USEP (Union Sportive education du Premier Degré) works in Morocco and Dutch NSA (Netherlands Sport Alliance) in the Dutch Antilles. One can only hope that there are further good reasons than simply colonial ties or delayed strikes of conscience to become involved with the complexities of sports and development.

\section{CONSEQUENCES:}

The risk of government involvement in sport and development based on geo-political rationale (Canada and Australia) is that sport is instrumentalised to the extreme. Sport can risk being "added" to development projects with unclear methodologies and goals. (Note that the Canadian and Australian examples do run some of the most qualified, long-term, and cross-cutting development projects. "Plus Sport" projects, in the terminology of Fred Coalter (2008)).

Party political reasons are slightly different. In the case of UISP, the risk exists that the projects are used more for political purposes (general advocacy for the right to sport as well as for profiling the involved organizations) than for their qualified content within the projects.

\section{REASON \#4: ORGANIZATIONAL DEVELOPMENT}

"What is in it for my organization?" is not an overly egoistic question to ask before commencing a sport and development Project.

1) Education. Extensive non-formal education programs for coaches, organizational lea- ders, trainers and practitioners seem increasingly to be on the rise including content on international trends, intercultural dialogue, etc. Indeed some specific educational modules are even executed abroad. Sport and development project partners offer an opportunity for such cooperation in education, and come to the table with interesting and often strikingly different cultural approaches to sport.

2) Sport and sport management inspiration. Whether it is in terms of the innovation that NGOs in Brazil display to develop football and volleyball under very difficult circumstances, or hip dance moves from Uganda or other ways of using (limited) public spaces for sport, these actions offer inspiration. This is especially true with respect to grass-root sport, where the activities need not follow strict regulations and where inspiration from other countries can be significant.

3) Political development. Most sport and development projects focus on organizational capacity building and advocacy. What is often overlooked is that the donor organization also needs political recognition to sustain its organization and to raise funds, also beyond the formal sport and development partnership. And sport and development partnerships can dramatically add to the donor organization profiles, the value base, and render them attractive to their stakeholders. In short, donor organizations could enter into sport and development projects simply to benefit their own national organizational (and financial) development image. 


\section{CONSEQUENCES FOR DANISH SPORT AND DE- VELOPMENT EFFORTS}

Organizations should clearly define their reasons for entering into sport and development projects and their rationale should be reflected in the manner in which the projects are conducted.

Even if the reasons of the donor organizations were well defined, much of the project rationale and the corresponding goals may indeed be achieved by other means than sport and development projects (e.g. education projects or civil society development). I would argue that a thorough assessment of costs and benefits of sport and development endeavors be compared with alternatives - or simply doing nothing at all. After all, interventions may raise more problems than solutions (cf. the "Do-no-harm" approach).

Danish donor sport organizations should focus on what they are in fact most competent at. General organizational capacity building or service delivery is not a unique Danish competence. Although this article will not discuss what Danish sport or specific Danish organizations can in fact uniquely contribute in developmental work abroad, this would be a worthy topic for public debate at a future time.

I would argue that donor sport organizations should look more closely at their own benefit from sport and development projects. In addition, they should consider more consistently developing these projects with recipient organizations that are as well on a national level in the respective countries. Sport and development projects with small and local NGOs may simply not render the same level of organizational benefits for the donor. And indeed national-to-national partnerships may have a higher degree of impact and sustainability for the recipients.

It is important to speculate whether (Danish) sport and development work will be impacted by the current financial crisis and the prioritization that it entails. I believe so. But had the rationale for why this work is initiated be both explicit and realistic (and perhaps align with organisational development arguments mentioned in this article), I believe that the work would prosper. Organizational development is indeed most important and especially in times of financial challenge. The area of sport and development is no exception. And it can deliver. 